\title{
Colonic mucin synthesis is increased by sodium butyrate
}

\author{
I A Finnie, A D Dwarakanath, B A Taylor, J M Rhodes
}

\begin{abstract}
The effects of sodium butyrate and sodium bromo-octanoate (an inhibitor of $\beta$ oxidation) on colonic mucus glycoprotein (mucin) synthesis have been assessed using tissue from colonic resection samples. Epithelial biopsy specimens were incubated for 16 hours in RPMI 1640 with glutamine, supplemented with $10 \%$ fetal calf serum and $\boldsymbol{N}$-acetyl- $\left[{ }^{3} \mathbf{H}\right]-$ glucosamine $\left(\left[{ }^{3} \mathbf{H}\right]-\right.$ Glc NAc), and differing concentrations of sodium butyrate. Incorporation of $\left[{ }^{3} \mathrm{H}\right]$ Glc NAc into mucin by normal epithelium at least $10 \mathrm{~cm}$ distant from colonic cancer was increased in the presence of sodium butyrate in a dose dependent manner, with maximum effect $(476 \%)$ at a concentration of $0.1 \mathrm{mM}$ (number of specimens $=24$ from six patients, $p<0.001)$. The increase in response to butyrate was not seen when specimens were incubated in the presence of the $\beta$ oxidation inhibitor sodium bromo-octanoate $0.05 \mathrm{M}$. The striking increase in mucin synthesis that results when butyrate is added to standard nutrient medium suggests that this may be an important mechanism affecting the rate of mucin synthesis in vivo and may also explain the therapeutic effect of butyrate in colitis.
\end{abstract}

(Gut 1995; 36: 93-99)

Keywords: sodium butyrate, colonic mucin synthesis.

The primary function of colonic mucus is considered to be protection of the surface mucosal cells. ${ }^{1}$ Mucus forms a gel that adheres to the epithelium, preventing invasion by colonic bacteria and protecting against damage by bacterial toxins and enzymes. Most of the protective effect of mucus is thought to relate to the presence of mucin, the predominant glycoprotein in mucus. Abnormalities of mucin have been shown in ulcerative colitis using histochemical, ${ }^{2}$ biochemical, ${ }^{3}$ and tissue culture techniques, ${ }^{45}$ and an attractive hypothesis for ulcerative colitis is that a primary abnormality of mucin synthesis predisposes subjects to an as yet undefined environmental factor that induces the disease. ${ }^{6}$

Exacerbations of ulcerative colitis can be successfully treated with sodium butyrate, ${ }^{7}$ although the exact mode of its action is not clear. Butyrate is an important source of energy for the colonic epithelial cells, ${ }^{8}$ and a local deficiency of butyrate ${ }^{9}$ or an inborn error in its metabolism ${ }^{10}$ have been implicated in the disease. We have investigated the effects of sodium butyrate on colonic mucin synthesis; if mucin synthesis were enhanced by butyrate this might help to explain its therapeutic mode of action.

\section{Methods}

MUCOSAL BIOPSY SPECIMENS

Fresh colonic tissue was obtained from patients undergoing colectomy for cancer ( $n=6$, median age 70,3 men 3 women), colonic inertia $(n=2$, ages 26 and 39, both women) or ulcerative colitis that was unresponsive to medical treatment $(n=2$, ages 55 and 32 , both men). Bowel preparation consisted of clear fluids for 48 hours and Picolax two sachets on the day before operation, except in the patients with ulcerative colitis in whom no formal bowel preparation was used (although as a result of their illness they also had been taking very little residue). The site of colonic cancer was rectum $(n=1)$, sigmoid $(n=3)$, and ascending colon $(n=2)$; the tissue studied was from sites at least $10 \mathrm{~cm}$ distant from the macroscopic disease, and in each case histological examination of adjacent mucosa confirmed that there was no abnormality. In the patients with colonic inertia, tissue from the ascending and descending colon was studied separately. In the patients with ulcerative colitis, the comparatively uninvolved right colon was studied. These two patients had been treated with high dose intravenous corticosteroids for at least 10 days, and had been receiving maintenance 5-aminosalicylic acid drugs before relapse, but neither had been treated with butyrate enemas.

The resected tissue was pinned out, and multiple mucosal specimens each weighing about $20 \mathrm{mg}$ were separated from underlying tissue using a scalpel. Specimens were then cultured as described below.

\section{TISSUE CULTURE}

Mucosal specimens were cultured using a technique based on that described by Macdermott et al. ${ }^{11}{ }^{12}$ Each specimen was placed on an alloy mesh (David, Wellingborough, UK), orientated so that the epithelial surface was uppermost. The wire grid was floated on $1 \mathrm{ml}$ culture medium in an organ culture dish (Becton Dickinson, NJ, USA). The culture medium was $90 \%$ RPMI 1640 with glutamine (Gibco, Paisley, UK) and 10\% fetal calf serum (Gibco) with gentamicin $100 \mu \mathrm{g} / \mathrm{ml}$ and nystatin $60 \mu \mathrm{g} / \mathrm{ml}$, to which was added 1.5
Correspondence to: Dr J M Rhodes, Department of Medicine, University of Liverpool L69 3BX.

Accepted for publication 12 April 1994 

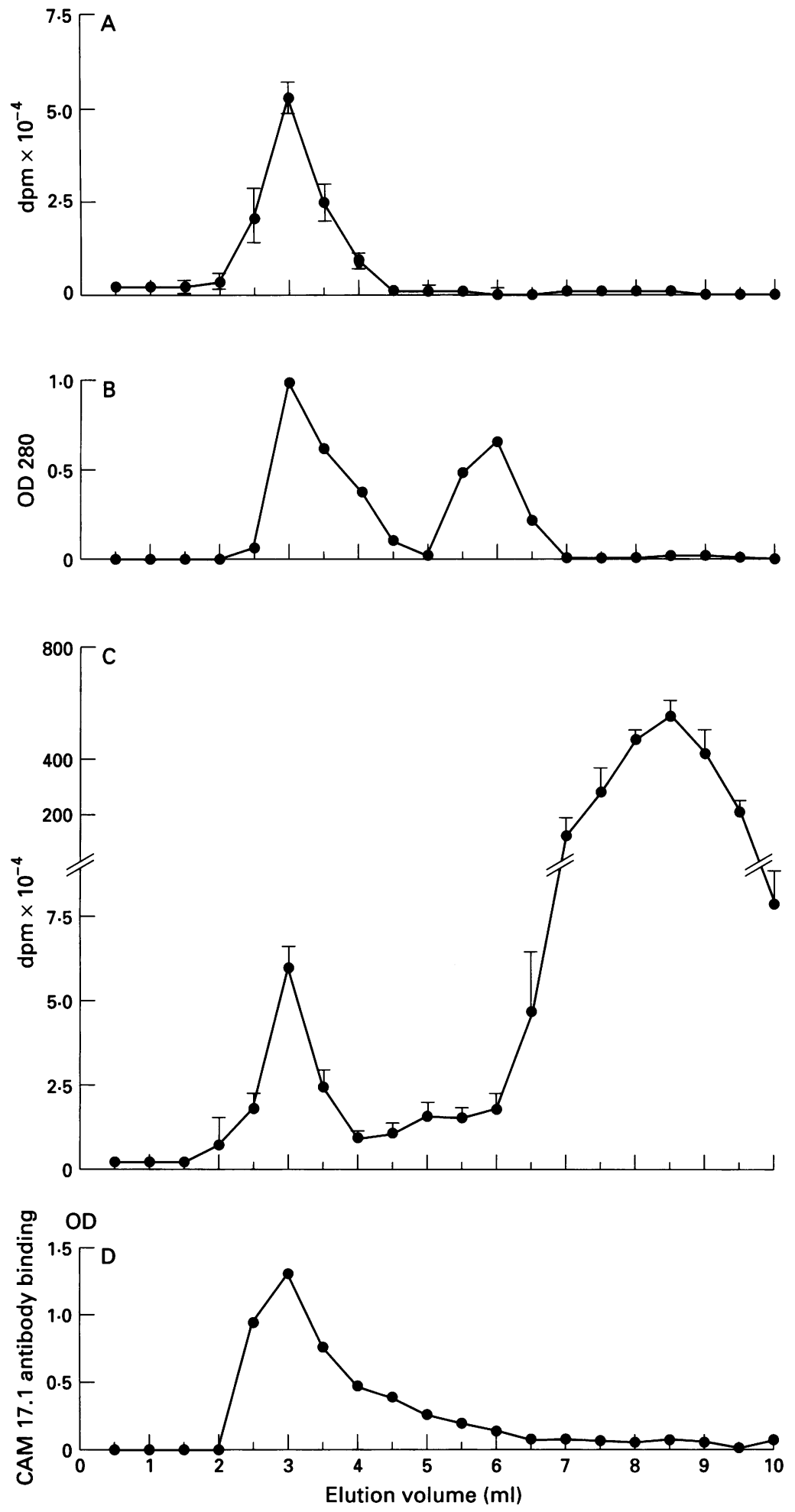

Figure 1: Calibration of mini-columns containing Sepharose CL-2B. Elution profile of aliquots of $(A)\left[{ }^{3} \mathrm{H}\right]$ Glc NAc labelled Superose 6-purified mucin, (B) blue dextran $\left(M W 2 \times 10^{6} \mathrm{Da}\right)$ and bovine serum albumin (MW $\left.67000 \mathrm{Da}\right)$. (C) Radiolabelled mucin (as in 1A), which has been 'spiked' by addition of $\left[{ }^{3} \mathrm{H}\right] \mathrm{Glc} N \mathrm{NAc}$ showing clear separation of mucin (first peak in void volume) from Glc NAc. (D) Shows CAM 17.1 (anti-mucin antibody) binding assay of Sepharose $C L-2 B$ separated mucin showing a single peak corresponding to the mucin fractions.

$\mu \mathrm{Ci} / \mathrm{ml} N$-acetyl-D- $\left[1-{ }^{3} \mathrm{H}\right]$ glucosamine $\left(\left[{ }^{3} \mathrm{H}\right]\right.$ Glc NAc) (Amersham, Little Chalfont, UK). Fifty $\mu l$ aliquots of solutions of sodium butyrate at varying concentrations (Sigma, Poole, UK) or $0.05 \mathrm{M}$ sodium bromooctanoate (Sigma), or both, dissolved in $0.1 \mathrm{M}$ TRIS (hydroxymethyl) methylamine/ $\mathrm{HCl} \mathrm{pH}$ 8 were added, except for the control specimens to which $50 \mu \mathrm{l}$ TRIS/HCl was added. Culture was for 18 hours at $37^{\circ} \mathrm{C}$ in $95 \% \mathrm{O}_{2} / 5 \% \mathrm{CO}_{2}$, except in one experiment, when varying periods of culture were used to assess specimen viability. A parallel time course experiment was conducted to exclude the possibility that colonic bacteria were incorporating the radiolabel, whereby $50 \mu$ l of faecal fluid taken from the lumen immediately after colectomy, in the absence of a mucosal biopsy specimen, was added to the culture system.

\section{ESTIMATION OF MUCIN SYNTHESIS}

At the end of the culture period, the mucosal surface of each specimen was gently rinsed in its culture medium to remove secreted but adherent mucus, placed in $1.3 \mathrm{ml} 0.1 \mathrm{M}$ TRIS/HCl at $\mathrm{pH} 8$ (TRIS/ $\mathrm{HCl}$ ) containing thimerosal $100 \mathrm{mg} / \mathrm{l}$ and sonicated using an MSE ultrasonic disintegrator (MSE Instruments, Crawley, UK). Each sample was then centrifuged for 15 minutes at $11000 \mathrm{~g}$ and $1 \mathrm{ml}$ of the supernatant retained and lyophilised after removal of a $100 \mu \mathrm{l}$ aliquot for protein estimation using a bicinchoninic acid protein assay kit (Sigma, St Louis, USA). The culture medium was also retained and lyophilised separately from the specimen.

After lyophilisation, each sample was resuspended in $200 \mu \mathrm{l}$ water and subjected to gel filtration using gravity fed mini-columns (PD 10) packed with Sepharose CL-2B (Pharmacia, Uppsala, Sweden). The samples were then eluted with deionised distilled water at a rate of $0.5 \mathrm{ml} / \mathrm{min}$, the samples containing mucin (void volumes) retained, mixed with 5 ml scintillant (Optiphase Safe, Pharmacia), and counted in a Rackbeta $\beta$ counter (LKB Wallace, Turku, Finland).

Total mucin synthesis was expressed as dpm [ $\left.{ }^{3} \mathrm{H}\right] \mathrm{N}$-acetylglucosamine incorporated into purified mucin (biopsy specimen plus culture medium) per $\mu \mathrm{g}$ biopsy protein.

CALIBRATION OF GEL FILTRATION COLUMNS AND VERIFICATION OF MUCIN PURITY

The gel filtration columns containing Sepharose CL-2B were calibrated using purified $\left[{ }^{3} \mathrm{H}\right]$ Glc NAc labelled mucin, which was obtained by culturing mucosal biopsy specimens as described above, preparing crude mucin by sonication of the specimens in TRIS/ $\mathrm{HCl}$, and subjecting this crude mucin to gel filtration using monodisperse agarose (Superose 6) (Pharmacia) using the method of Parker et al. ${ }^{13}$ The fractions containing purified mucin were pooled, lyophilised, reconstituted with $200 \mu \mathrm{l}$ water, and then subjected to gel filtration using the Sepharose CL-2B columns. Deionised distilled water was added in $0.5 \mathrm{ml}$ aliquots at a rate of $0.5 \mathrm{ml} / \mathrm{min}$. Twenty $0.5 \mathrm{ml}$ fractions were collected, mixed with scintillant, and $\beta$ counted. The elution profile of $1 \mu \mathrm{Ci}$ $\left[{ }^{3} \mathrm{H}\right]$ Glc NAc in $200 \mu \mathrm{l}$ TRIS/ $\mathrm{HCl}$ was studied as a comparison.

Superose 6 purified mucin that was labelled with $\left[{ }^{3} \mathrm{H}\right]$ Glc NAc was found to elute reproducibly from the Sepharose CL-2B columns between 2 and $3.5 \mathrm{ml}$ (Fig 1A). Figure 1B 

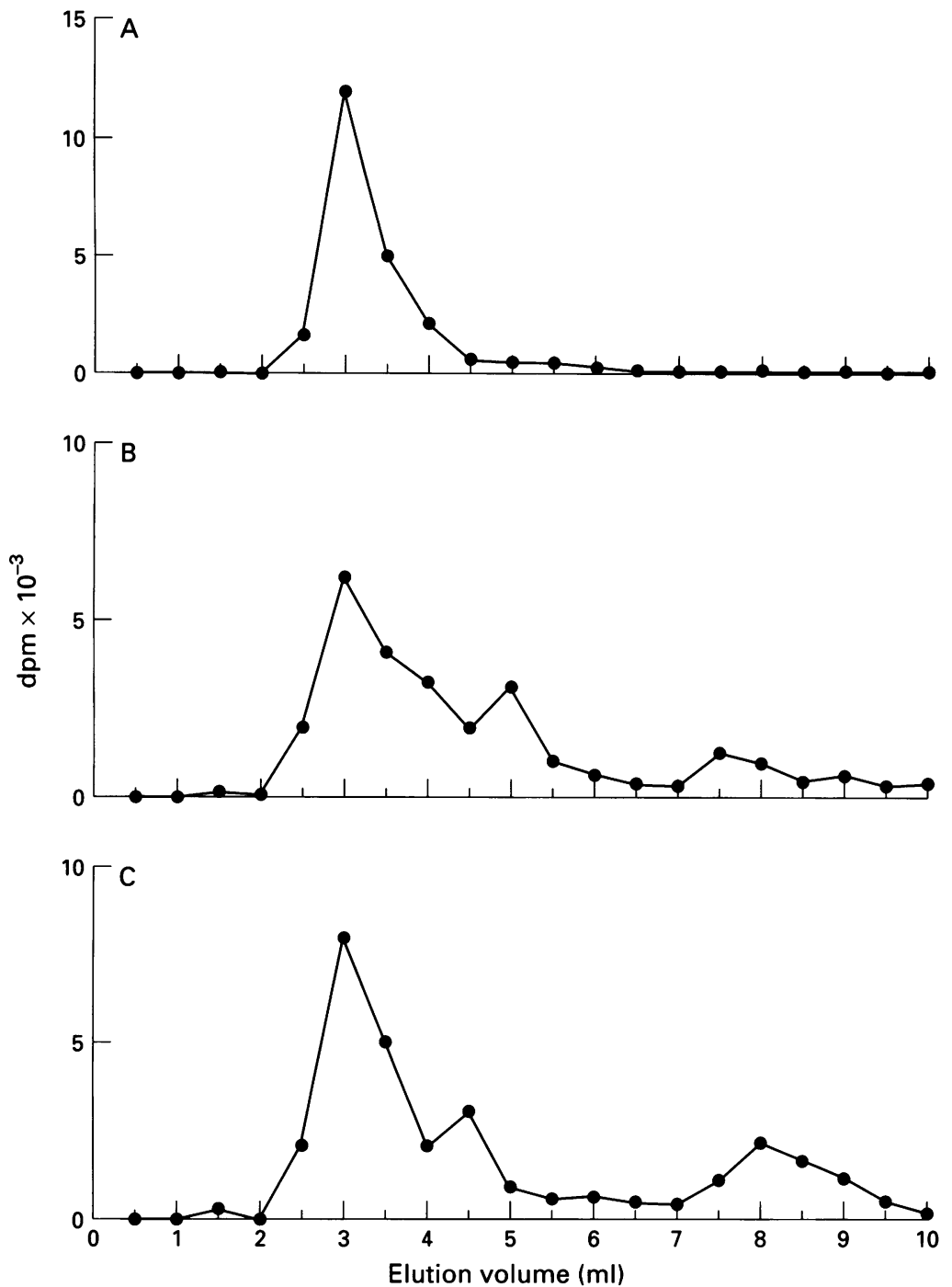

Figure 2: Protease digestion of Sepharose $C L-2 B$ purified [ ${ }^{3} \mathrm{H}$ Glc Nac] labelled mucin. Mucin was incubated with $(A)$ phosphate buffered saline as a control, $(B)$ pronase, or $(C)$ trypsin, and then subjected to repeat gel filtration using Sepharose $C L-2 B$ mini-columns. The protease incubated mucin fragments mainly into large and medium sized glycoproteins (see comparison with Fig 1B). The profile shown is for mucin secreted into culture medium, but similar profiles were obtained for biopsy specimen homogenates and incubation with proteoglycan degrading enzymes had no effect on subsequent elution profiles.

shows the elution profile of a mixed solution of blue dextran (MW $2 \times 10^{6} \mathrm{Da}$ ) (Pharmacia) and bovine serum albumin (MW $67000 \mathrm{Da}$ ) on the mini-columns. Elution of $\left[{ }^{3} \mathrm{H}\right]$ Glc NAc occurred separately, and addition of $1 \mu \mathrm{Ci}$ to labelled mucin produced no significant change in scintillation in the mucin containing fractions confirming lack of non-specific binding (Fig 1C). The yield of $\left[{ }^{3} \mathrm{H}\right]$ Glc NAc labelled mucin (mean (SD)) from the Sepharose CL2B columns was $95(4) \%, n=6)$.

Fractions of Sepharose CL-2B separated mucin were also analysed using an enzyme linked mucin antibody (CAM 17.1) binding assay ${ }^{13}$ (Fig 1D), which confirmed the elution of mucin in the void volume.

To assess the comparative purity of the mucin samples obtained using Sepharose CL-2B gel filtration, aliquots of $\left[{ }^{3} \mathrm{H}\right]$ Glc NAc labelled mucin (about $0.2 \mu \mathrm{g}$ protein as determined by bicinchoninic acid) purified from specimens and medium using this technique were incubated in the presence of (a) hyaluronidase (hyaluronoglucosaminidase, Boehringer, Lewes, UK) $1 \mathrm{mg} / \mathrm{ml}$ at $\mathrm{pH} 5.0$ for one hour at $37^{\circ} \mathrm{C}$, (b) collagenase (Sigma) 10 $\mathrm{mg} / \mathrm{ml}$ at $\mathrm{pH} 7.4$ for five hours at $37^{\circ} \mathrm{C}$, (c) chondroitinase $\mathrm{ABC}$ (Boehringer) $0.01 \mathrm{U}$ at $\mathrm{pH} 8$ for one hour at $37^{\circ} \mathrm{C}$, (d) pronase $(\mathrm{BDH})$ 7000 PUK units at $\mathrm{pH} 7.6$ for one hour at room temperature, (e) bovine pancreas trypsin (EC 3.4.21.4) (Sigma) about 100000 units for one hour at room temperature or ( $f$ ) in phosphate buffered saline as controls. The samples were then cooled, and repeat gel filtration using Sepharose CL-2B mini-columns was performed. The fractions were collected, mixed with scintillant, and $\beta$ counted.

Incubation of $\left[{ }^{3} \mathrm{H}\right]$ Glc NAc labelled mucin with hyaluronidase, collagenase, and chondroitinase had no effect on the subsequent elution profiles, whether the mucin studied had been purified from biopsy specimen or culture medium: however, a small $(<5 \%)$ loss in recovery was seen after incubation with hyaluronidase of mucin purified from culture medium. Pronase and trypsin caused a change in the elution profile of the labelled mucin (Figs 2 and 3), but with much of the radiolabel still detectable in high molecular weight components, in keeping with the known protease resistance of mucin subunits. ${ }^{14}$

Glycolipid contamination was assessed by extracting Sepharose CL-2B purified mucin labelled with $\left[{ }^{3} \mathrm{H}\right]$ Glc NAc with two volumes chloroform/methanol 2:1. The chloroform and aqueous layers were separated, mixed with scintillant, and their radioactivity counted. Washing with chloroform/methanol reduced subsequent recovery of mucin by $2 \cdot 5(3 \cdot 2) \%$ (mean (SD), $\mathrm{n}=5$ ) showing minimal contamination by glycolipids.

In addition, aliquots of $\left[{ }^{3} \mathrm{H}\right]$ Glc NAc labelled mucin purified on Sepharose CL-2B were collected, lyophilised, and subjected to gel filtration using Superose 6 . The fractions were mixed with scintillant and $\beta$ counted. These were compared with the results obtained by purifying aliquots of the same sample using Superose 6 gel filtration alone. $\left[{ }^{3} \mathrm{H}\right]$ Glc NAc labelled mucin purified using Sepharose CL$2 B$ eluted in the same position as pure mucin when subsequently subjected to gel filtration using Superose 6, 85 (9) (mean (SD)) per cent eluting between fractions 7-10 (Fig 4), which previous studies ${ }^{12}{ }^{13}$ have shown to be free from contaminating non-mucin glycoproteins.

\section{TIME COURSE OF MUCIN SYNTHESIS AND}

LACTATE DEHYDROGENASE RELEASE

There was a noticeable lag period of six to eight hours when the rate of incorporation of $\left[{ }^{3} \mathrm{H}\right]$ Glc NAc into mucin was low, followed by a period when the rate of mucin synthesis (total of mucin in biopsy specimen + culture medium) was roughly linear for up to 26 hours (Fig 5). Radiolabelling of mucin in the biopsy specimen homogenate mucin increased gradually to a peak at around 20 hours, whereas it continued to rise in the culture medium for the duration of the experiment. Culture of faecal fluid without biopsy specimen had no significant effect on incorporation of radiolabel into the Sepharose CL-2B column void volume. 

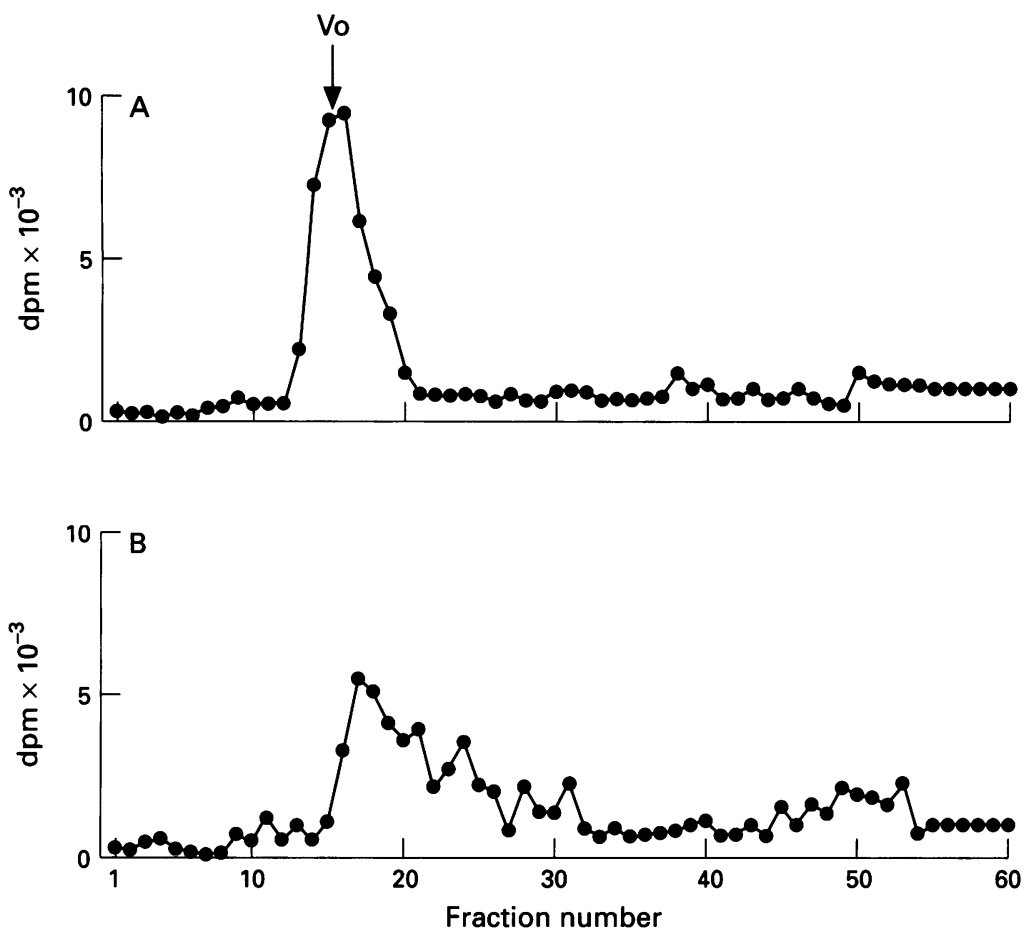

Figure 3: Elution profile of (A) Sepharose CL-2B mini-column purified [ $\left.{ }^{3} \mathrm{H}\right] \mathrm{Glc} N A \mathrm{C}$ labelled mucin on a $60 \mathrm{ml}$ column containing Sepharose $C L-4 B, 13$ and $(B)$ after digestion with pronase. Vo=void volume.
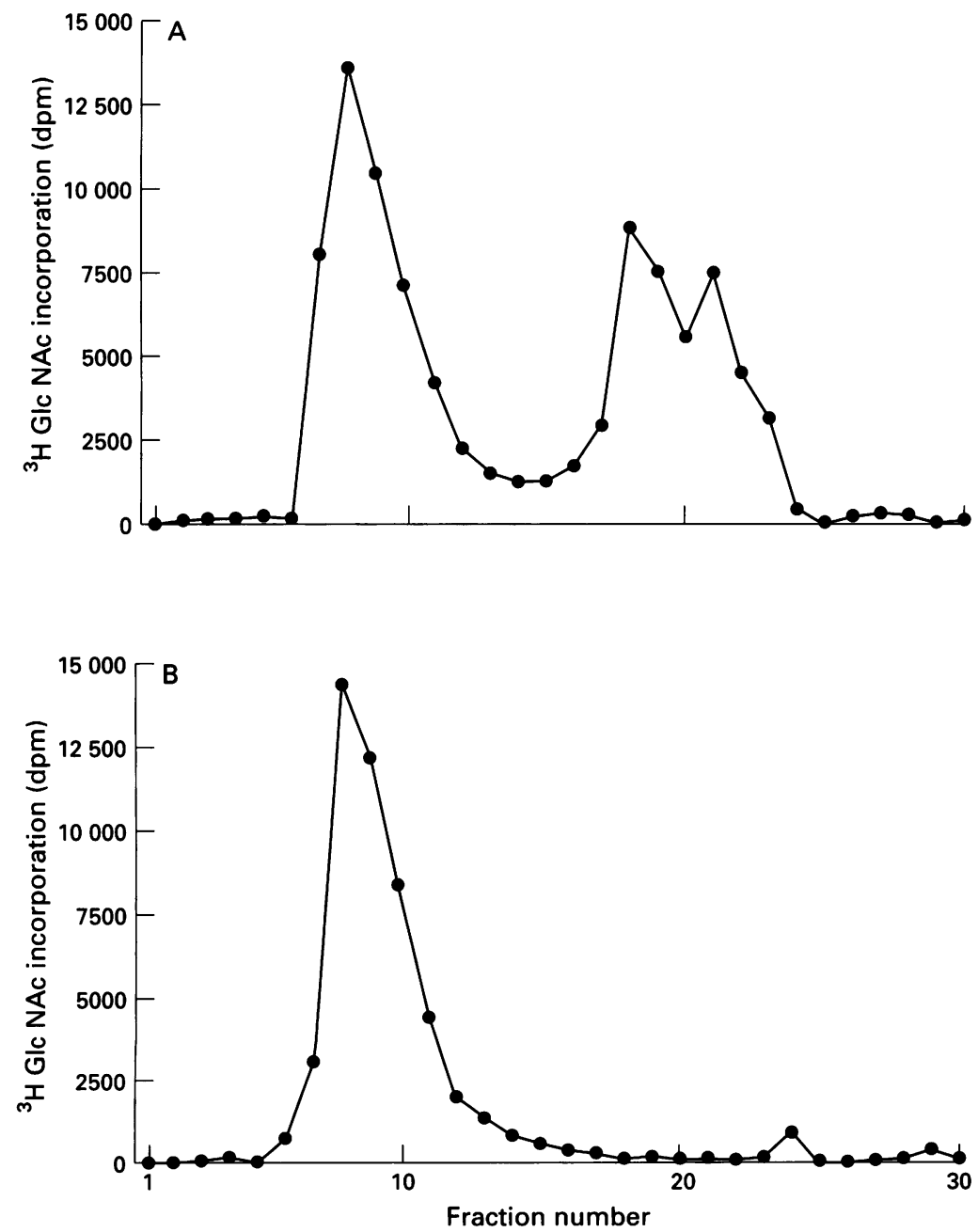

Figure 4: Superose 6 gel filtration of aliquots of $(A)$ crude $\left[{ }^{3} \mathrm{H}\right]$ Glc NAc labelled mucin and $(B)$ aliquots of mucin used in $(A)$ that has previously been purified using Sepharose $C L-2 B$, showing little contamination by non-mucin glycoprotein ${ }^{13}$ in the Sepharose $C L-2 B$ purified mucin.
REPRODUCIBILITY

The mean coefficient of variation for the incoporation of $\left[{ }^{3} \mathrm{H}\right]-\mathrm{N}$-acetyl glucosamine into mucin by different (histologically normal) colonic biopsy specimens from the same area of the colon and patient (expressed in comparison with biopsy specimen protein content) was $16 \%$ in non-treated $(\mathrm{n}=44$ biopsy specimens, 8 patients), and $20 \%$ in butyrate treated specimens ( $n=164$ specimens, 8 patients). In UC the mean coefficient of variation was $21 \%$.

\section{LACTATE DEHYDROGENASE RELEASE}

In a further experiment, biopsy specimens were cultured as described above but without radiolabel for 24 hours, with changes of culture medium every four hours. The culture medium was kept at $-40^{\circ} \mathrm{C}$ for up to 24 hours, and then analysed for lactate dehydrogenase using the colourimetric method of Jones et al. ${ }^{15}$ Specimens were ultrasonicated in $1 \mathrm{ml}$ TRIS/ $\mathrm{HCl}$ at the end of the culture period and lactate dehydrogenase activity (after 1/50 dilution) and protein concentration assessed.

Lactate dehydrogenase release into the culture medium was high during the first four hour period (possibly because of leakage of enzymes from the cut surface). Thereafter the rate of release was steady throughout the 24 hour culture period, and was low in comparison with the biopsy specimen content at the end of the culture period (Table).

\section{STATISTICAL ANALYSIS}

Comparisons of the values obtained for mucin synthesis in the presence of different concentrations of butyrate and bromo-octanoate of the drugs studied were made by non-parametric analysis of variance (Kruskal-Wallis) followed by multiple paired comparisons. Comparisons between the left and right colon were made by the Mann-Whitney $U$ test. Differences were considered significant at $\mathrm{p}<0.05$.

\section{Results}

EFFECT OF SODIUM BUTYRATE AND SODIUM BROMO-OCTANOATE ON MUCIN PRODUCTION

\section{Histologically normal tissue}

Control biopsy specimens from the ascending colon (from the two patients with colonic inertia) showed a higher rate of total mucin synthesis than specimens from the descending colon (ascending 35.2 (11.8) (mean (SD), $\mathrm{n}=10) \mathrm{dpm} / \mu \mathrm{g}$ protein $/ \mathrm{h}$, descending $25 \cdot 5$ $(10.6) \quad(n=10), \quad p<0.05) . \quad$ Histologically normal tissue from the ascending colon and descending colon from patients with carcinoma showed a much wider variation (ascending $26.4(16.2) \mathrm{dpm} / \mu \mathrm{g}$ protein $/ \mathrm{h}$, descending $21 \cdot 9(15 \cdot 3))$.

There was an increase in mucin synthesis when specimens from the patients with colon cancer were incubated in the presence of 


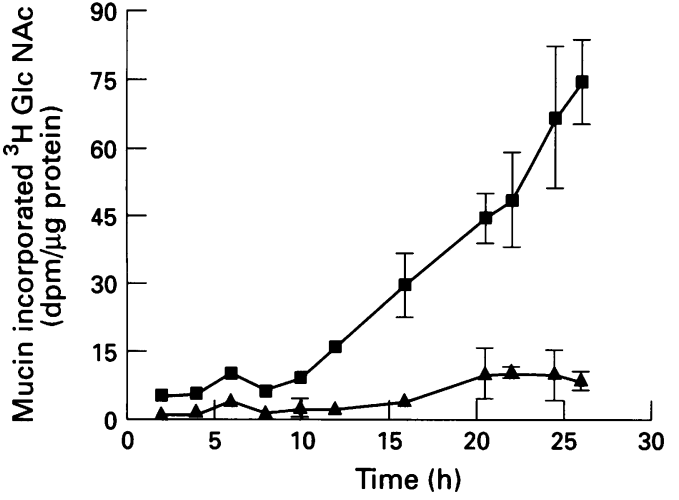

Figure 5: Time course for incorporation of $\left[{ }^{3} \mathrm{H}\right] \mathrm{Glc} N A \mathrm{c}$ into mucin by colonic biopsy specimens (from a patient with colonic cancer). $\boldsymbol{\Delta}=$ biopsy specimen mucin, $\boldsymbol{D}=$ sum of biopsy specimen and culture medium mucin. Note the time lag with little incorporation of $\left[{ }^{3} \mathrm{H}\right] \mathrm{Glc} N A \mathrm{c}$ into mucin in the first six to eight hours, followed by a period when the rate of incorporation is roughly linear.

sodium butyrate at all concentrations tested. The effect was most noticeable at concentrations between $0 \cdot 1-1 \mathrm{mM}$; the increase was statistically significant at all concentrations tested except at the lowest $(0.05 \mathrm{mM})$ and at the highest (10 mM) (Fig 6).

The increases in mucin synthesis were of a similar magnitude when specimens from the ascending and descending colon of the same patients (with colonic inertia) were incubated with sodium butyrate at $0 \cdot 1 \mathrm{mM}$ (ascending 272 (168)\% (mean (SD)), descending 306 (108), $\mathrm{n}=10$ ); $0.5 \mathrm{mM}$ (ascending 417 (257), descending 475 (349), $\mathrm{n}=10$ ); and $1 \mathrm{mM}$ (ascending 297 (178), descending 309 (197), $\mathrm{n}=10$ ).

A concentration of $0.05 \mathrm{M}$ sodium bromooctanoate did not itself have any effect on mucin production, but abolished the butyrate induced increase in mucin production (Fig 7).

Mucin recovered from the medium accounted for 73 (12)\% (mean (SD)) of mucin synthesised during the 16 hour culture period.

\section{Ulcerative colitis}

The rate of mucin synthesis in 10 specimens from the two ulcerative colitis patients $(24 \cdot 6$ $(12 \cdot 2) \mathrm{dpm} / \mu \mathrm{g}$ protein/h) (mean (SD)) was marginally (not significantly) lower than the rate seen in the right colon in histologically normal tissue. When specimens from the patients with ulcerative colitis were incubated in the presence of sodium butyrate at $0 \cdot 1$

Content and release of lactate dehydrogenase by colonic biopsy specimens in culture. Specimens were cultured for 24 hours, during which period the culture medium was changed at four hourly intervals. Medium and biopsy samples were assayed for lactate dehydrogenase activity, corrected for protein concentration

\begin{tabular}{lc}
\hline $\begin{array}{l}\text { Culture medium } \\
\text { time }\end{array}$ & $\begin{array}{l}\text { Lactate dehydrogenase } \\
\text { m units/h/mg/protein } \\
\text { (mean }(S E M) n=4)\end{array}$ \\
\hline $0-4$ hours & $135 \cdot 2(48 \cdot 1)$ \\
$4-8$ hours & $75 \cdot 2(18 \cdot 3)$ \\
8-12 hours & $45 \cdot 3(21 \cdot 0)$ \\
$12-16$ hours & $32 \cdot 2(8 \cdot 8)$ \\
16-20 hours & $39 \cdot 8(10 \cdot 3)$ \\
16-24 hours & $29 \cdot 7(14 \cdot 5)$ \\
Biopsy specimen (after 24 hours) & $1988(202)$ \\
\hline
\end{tabular}

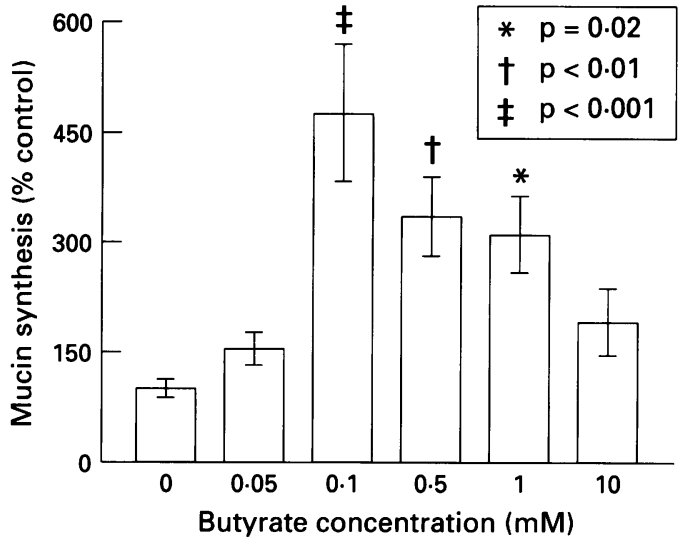

Figure 6: Effect of sodium butyrate at differing concentrations on mucin synthesis by colonic biopsy specimens from the patients with colonic cancer. These specimens were from colonic epithelium that was macroscopically normal, and adjacent specimens were histologically normal. Mucin synthesis is expressed as \% control for biopsy specimen (non-secreted) and medium (secreted) mucin combined. The increase in mucin synthesis compared with controls $(n=24)$ was significant at $p<0.001$ for concentration $0.1 \mathrm{mM}(n=24)$, at $p<0.01$ for $0.5 \mathrm{mM}(n=20)$, at $p=0.02$ for $1 \mathrm{mM}(n=24)$. At concentrations $0.05 \mathrm{mM}(n=12, p=0.56)$ and $10 \mathrm{mM}$ $(n=24, p=0.07)$ the increase did not reach statistical significance.

$\mathrm{mM}, 0.5 \mathrm{mM}$, and $1 \mathrm{mM}$ there was an increase in the rate of mucin synthesis, which was less pronounced than that seen in histologically normal tissue, and was significant only at a concentration of $0.5 \mathrm{mM}$ (Fig 8).

\section{Discussion}

This study has shown that in vitro mucin synthesis by colonic biopsy specimens occurs at a linear rate from six to 28 hours, can be stimulated over fourfold by sodium butyrate, and that this stimulatory effect is abolished by the inhibitor of $\beta$ oxidation, sodium bromooctanoate.

We found a lag period after starting the culture, during which there was little measurable incorporation of radiolabel by colonic specimens. Although some studies of glucosamine incorporation do not report a lag

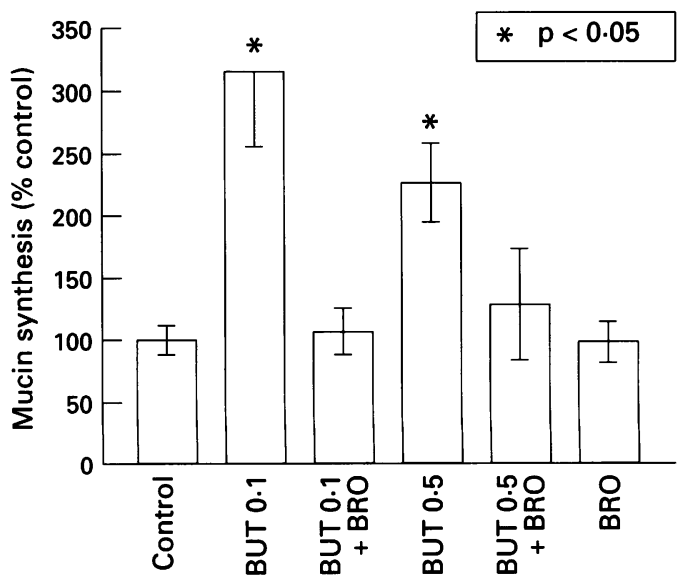

Figure 7: Effect of 0.05-1 mM sodium butyrate (BUT) and $0.05 \mathrm{M}$ sodium bromo-octanoate (BRO) on mucin synthesis by colonic epithelial biopsy specimens. Mean (SEM) for 12 biopsy specimens (from three patients) in each group. 


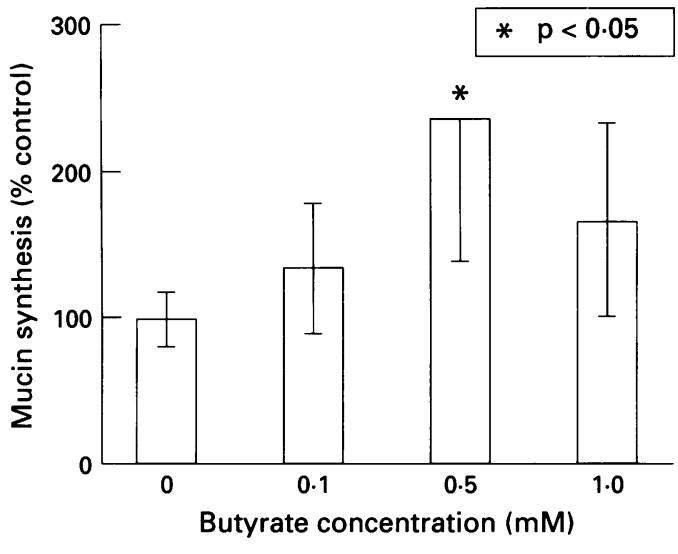

Figure 8: Effect of sodium butyrate on mucin synthesis by colonic biopsy specimens from two patients with ulcerative colitis. Each point represents mean (SEM) for 10 specimens. In comparison with specimens cultured without butyrate, mucin synthesis was significantly increased at $0.5 \mathrm{mM}(p<0.05)$

period, ${ }^{16}$ others do, ${ }^{17}$ and it is probable that this represents the time taken for the radiolabel to be incorporated into completely synthesised mucus glycoprotein. Incompletely glycosylated mucins may not be excluded by Sepharose CL$2 \mathrm{~B}$, and it should be remembered that the time for newly formed glycoprotein to appear at the apical cell surface of human goblet cells is six to eight hours. ${ }^{18}$ After the lag period, specimens synthesised mucin at a constant rate.

Lactate dehydrogenase release from specimens in culture was roughly linear over 24 hours, and the rate of release was small in comparison with whole tissue lactate dehydrogenase activity. This shows that the tissue remains viable throughout the culture period ${ }^{15}$ and this is further supported by the linear incorporation of radiolabelled substrate into mucin throughout the culture period.

A purification step of some kind is important in studies of mucin synthesis as $50 \%$ of radiolabelled hexosamine may be incorporated into non-mucin glycoprotein by the epithelium in culture. ${ }^{19}$ The rapid single stage technique of mucin purification described here has the advantage that multiple samples can be purified simultaneously. The mucin thus obtained has been shown to be free from significant contamination by glycolipids and proteoglycans, and the comparative resistance to protease digestion and the high molecular weight fragments that result are strong evidence that the purified radiolabelled substance is largely mucin. ${ }^{14}$ Mucin does not interfere with the elution of free radiolabelled GlcNAc, and the free radiolabel and mucin are well separated.

This study shows the importance of assessing the culture medium in addition to the biopsy specimen homogenate when assessing mucin synthesis, as about three quarters of incorporated radiolabel in this study was found to be in mucin, which has been secreted into the medium. This is rather more than was found in previous studies, ${ }^{511}$ probably because incompletely glycosylated intracytoplasmic mucins were not excluded by the Sepharose CL-2B. Mucin purification by acid precipita- tion $^{5}$ will probably result in the co-purification of small and medium sized glycoproteins with mucin, and these smaller molecules (including incompletely glycosylated mucins) are more likely to be found in the tissue homogenate than in secretions.

Butyrate, which is formed in the colon by bacterial fermentation of dietary fibre, is the preferred energy source of colonic epithelial cells and stimulates oxygen utilisation by isolated colonocytes in culture. ${ }^{8}$ The luminal butyrate concentration is reduced by fasting, ${ }^{20}$ and is increased specifically in the proximal colon by ingestion of easily fermentable fibres (for example, oats, guar), and in the distal colon by ingestion of wheat bran, which is less easily fermentable. ${ }^{21}$ Butyrate reduces proliferation and differentiation in colonic cancer cell lines in vitro, ${ }^{22}$ but paradoxically increases proliferation in the normal colon, ${ }^{23}$ and a reduction in butyrate metabolism by the colonic epithelium has been proposed as a possible aetiological factor in carcinogenesis. ${ }^{24}$ The concentration of butyrate that induced maximal stimulation of mucin synthesis is 100 -fold less than that in the human colonic lumen, ${ }^{25}$ but the concentration in the portal blood is only $0.029 \mathrm{mM},{ }^{25}$ and the concentration bathing the epithelial cell in vivo may be considerably lower than that in the lumen. Although impaired butyrate metabolism has been reported in isolated epithelial cells extracted from the mucosa in ulcerative colitis $^{10}$ this was not confirmed in a recent study in which butyrate metabolism was studied using mucosal biopsy specimens. ${ }^{26}$ Nevertheless, butyrate reduces proliferation in the mucosa in ulcerative colitis, ${ }^{7}$ and butyrate enemas are an effective treatment for diversion colitis $^{27}$ and ulcerative colitis. ${ }^{7}$

Sodium bromo-octanoate inhibits fatty acid oxidation in perfused rat liver and in mitochondria isolated from rat liver, probably by inhibiting an enzyme of $\beta$ oxidation, ${ }^{28}$ and experimental colitis can be induced in laboratory animals by bromo-octanoate enemas. ${ }^{29}$ In this study sodium bromo-octanoate completely blocked the stimulatory effect of butyrate on mucin synthesis although when tested alone did not inhibit mucin synthesis. This suggests that the colonic epithelium, at least in short term culture, can use alternative sources of energy if $\beta$ oxidation is inhibited.

Goblet cell depletion of mucus is a characteristic histological feature of ulcerative colitis. ${ }^{30}$ Previous studies of mucin synthesis by ulcerative colitis biopsy specimens cultured in vitro have had conflicting conclusions, with reduced synthesis in inactive ulcerative colitis in one study, ${ }^{5}$ but normal in another. ${ }^{17}$ It has been argued that the increase in cell turnover seen with this disease ${ }^{31}$ should be accompanied by an increase in mucin synthesis, and that mucin synthesis is deficient compared with the rate of cell proliferation. ${ }^{32}$ If mucin synthesis and proliferation were directly linked, however, the expected response to butyrate in ulcerative colitis would be a decrease in mucin synthesis rather than the increase described here (as butyrate enemas 
are known to reduce epithelial proliferation in ulcerative colitis $\left.{ }^{7}\right)$. An alternative explanation is that by increasing mucin synthesis, butyrate increases mucosal protection, and this permits the rate of proliferation to reduce to a more normal rate, possibly by blocking the binding of luminal growth factors that might be dietary in origin ${ }^{33}$ or secreted locally. ${ }^{34}$ The increase in mucin synthesis induced by butyrate probably reflects an important therapeutic mode of action, as well as a physiological function.

Dr Finnie is supported by the Mersey Regional Health Authority and Dr Dwarakanath by the British Digestive Foundation and National Association of Colitis and Crohn's disease.

The authors would like to thank Mr M J Hershman for his cooperation in obtaining tissue samples.

1 Florey $\mathrm{H}$. Mucin and the protection of the body. Proc $R$ Soc Lond 1955; 143: 144-58.

2 Rhodes JM, Black RR, Savage A. Altered lectin binding by colonic epithelial glycoconjugates in ulcerative colitis and Crohn's disease. Dig Dis Sci 1988; 33: 1358-63.

3 Clamp JR, Fraser G, Read AE. Study of the carbohydrate content of mucus glycoproteins from normal and diseased colons. Clin Sci 1981; 61: 229-34

4 Raouf AH, Tsai HH, Parker N, Hoffman J, Walker RJ, Rhodes JM. Sulphation of colonic mucin in ulcerative colitis and Crohn's disease. Clin Sci 1992; 83: 623-6.

5 Cope GF, Heatley RV, Kelleher J, Axon ATR. In vitro mucus glycoprotein production by colonic tissue from patients with ulcerative colitis. Gut 1988; 28: $229-43$.

6 Rhodes JM. Colonic mucus and mucosal glycoproteins: the key to colitis and cancer? Gut 1989; 30: 1660-6.

7 Scheppach W, Sommer H, Kirchner T, Paganelli G-M, Bartram P, Christl S, et al. Effect of butyrate enemas on the colonic mucosa in distal ulcerative colitis. Gastroenterology 1992; 103: 51-6.

8 Roediger WEW. Role of anaerobic bacteria in the metabolic welfare of the colonic mucosa in man. Gut 1980; 21: 793-8.

9 Vernia P, Gnaediger A, Hauck W, Breuer RI. Organic anions and the diarrhea of inflammatory bowel disease. Dig Dis Sci 1988; 33: 1353-8.

10 Roediger WEW. The colonic epithelium in ulcerative colitis: an energy deficiency disease. Lancet 1980; ii: $712-5$.

11 MacDermott RP, Donaldson RM, Trier JS. Glycoprotein synthesis and secretion by mucosal biopsies of rabbit colon and human rectum. $\mathcal{f}$ Clin Invest 1974; 54: 545-54.

12 Raouf AH, Parker N, Iddon D, Ryder S, Langdon-Brown $\mathrm{B}$, Milton JD, et al. Ion-exchange chromatography of purified human colonic mucus glycoproteins in inflammatory bowel dis cot abic 1991; 32: 1139-45.

13 Parker N, Finnie IA, Raouf AH, et al. High performance gel filtration using monodisperse highly cross-linked agarose as a one-step system for mucin purification. Biomed Chromatogr 1993; 7: 68-74.

14 Gold DV, Shochat D, Miller F. Protease digestion of colonic mucin: evidence for the existence of two immunochemically distinct mucins. $f$ Biol Chem 1981; 262: 6354-8.
15 Jones DA, Jackson MJ, Edwards RHT. Release of intracellular enzymes from an isolated mammalian skeletal muscle preparation. Clin Sci 1983; 65: 193-201.

16 Morita H, Kettlewell MGW, Jewell DP, Kent PW. Glycosylation and sulphation of colonic mucus glycoproteins in patients with ulcerative colitis and in healthy subjects. Gut $1993 ; \mathbf{3 4}$ : 926-32.

17 Smith AC, Podolsky DK. Biosynthesis and secretion of human colonic mucin glycoprotein. $\mathcal{f}$ Clin Invest 1987; 80: human 7 .

18 Neutra MR, Grand RJ, Trier JS. Glycoprotein synthesis, transport, and secretion by epithelial cells of human rectal mucosa. Normal and cystic fibrosis. Lab Invest 1977; 36: 535-46.

19 Lukie BE, Forstner GG. Synthesis of intestinal glycoprotein. Incorporation of (1-14C) glucosamine in vitro. Biochim Biophys Acta 1972; 261: 353-64.

20 Illman RJ, Topping DL, Trimble RF. Effects of food restriction and starvation-refeeding on volatile fatty acid concentrations in the rat $\mathcal{F}$ Nutr 1986; 116: $1694-700$.

21 McIntyre A, Young GP, Taranto T, Gibson PR, Ward PB Different fibers have different regional effects on luminal contents of rat colon. Gastroenterology 1991; 101: contents

22 Gum JR, Kam WK, Byrd JC, Hicks J, Sleisenger MH, Kim YS. Effects of sodium butyrate on human colonic adenocarcinoma cells: induction of placental alkaline phosphatase. $\mathcal{F}$ Biol Chem 1987; 262: 1092-7.

23 Sakata T, Yajima T. Influence of short chain fatty acids on the epithelial division of digestive tract. $Q \mathcal{F}$ Exp Physio 1984; 69: 639-48.

24 Jass JR. Diet, butyric acid and differentiation of gastrointestinal tract tumours. Med Hypotheses 1985; 18: 113-8.

25 Cummings JH, Pomare EW, Branch WJ, Naylor LP, Macfarlane GT. Short chain fatty acids in human large
intestine, portal, hepatic and venous blood. Gut 1987; 28: intestine,

26 Finnie IA, Taylor BA, Rhodes JM. Ileal and colonic epithelial metabolism in ulcerative colitis: increased glutamine metabolism in distal colon but no defect in butyrate metabolism. Gut 1993; 34: 1552-8.

27 Harig JM, Soergel KH, Komorowski RA, Wood CM Treatment of diversion colitis with short-chain fatty acid irrigation. N Engl F Med 1989; 320: 23-8.

28 Raaka BM, Lowenstein JM. Inhibition of fatty acid oxidation by 2-bromooctanoate including effects of bromooctanoate on ketogenesis and gluconeogenesis. $f$ Bromooctanoate on ketogenesis

29 Roediger WE, Nance S. Metabolic induction of experimental ulcerative colitis by inhibition of fatty acid oxidation. Br f Exp Pathol 1986; 67: 773-82.

$30 \mathrm{McCormick}$ DA, Horton LWL, Mee AS. Mucin depletion in inflammatory bowel disease. $\mathcal{f}$ Clin Pathol 1990; 43: 143-6.

31 Allan A, Bristol JB, Williamson RCN. Crypt cell production rate in ulcerative proctcolitis: differential increments in remission and relapse. Gut 1985; 26: 999-1003.

32 Burton AF, Anderson FH. Decreased incorporation of $14 \mathrm{C}$-glucosamine relative to $3 \mathrm{H}-\mathrm{N}$-acetylglucosamine in the intestinal mucosa of patients with inflammatory bowel the intestinal mucosa of patients with inflammat $A m \mathcal{F}$ Gastroenterol 1983; 78: 19-22.

33 Ryder SD, Parker N, Ecclestone D, Haqqani M, Rhodes JM. Peanut lectin stimulates proliferation in colonic explants from patients with inflammatory bowel disease and colonic polyps. Gastroenterology 1994; 106: 117-24.

34 Wright NA. Trefoil peptides and the gut. Gut 1993; 34: 577-9. 